\title{
Thermionic properties of lutetium borides single crystals
}

\author{
D.A.Voronovich, A.A.Taran, N.Yu.Shitsevalova*, \\ G.V.Levchenko ${ }^{*}$, V.B.Filipov"
National Aerospace University "Kharkiv Aviation Institute", 17 Chkalov Str., 61070 Kharkiv, Ukraine
*I. Frantsevich Institute for Problems of Material Science, National Academy of Sciences of Ukraine, 3 Krzhyzhanovsky Str., 03680 Kyiv 142, Ukraine

\section{Received February 19, 2014}

\begin{abstract}
Results of the $\mathrm{LuB}_{12}(100),(110),(111), \mathrm{LuB}_{4}(001), \mathrm{LuB}_{2}(001)$ thermionic properties study in the temperature range $T=1200 \ldots 1960 \mathrm{~K}$ at $p \leq 10^{-4} \mathrm{~Pa}$ pressure are presented. The correlation between structure and composition of the lutetium borides single-crystal samples and their thermionic properties are shown. The electron work function anisotropy of the $\mathrm{LuB}_{12}$ low-index planes are determined by the lutetium and boron atoms reticular density and the electric dipole moment of the unreconstructed (100), (110), (111) planes of the $\mathrm{UB}_{12}$ type lattice structure.
\end{abstract}

Представлены результаты исследований термоэмиссионных свойств $\mathrm{LuB}_{12}$ (100), (110), (111), $\mathrm{LuB}_{4}(001), \mathrm{LuB}_{2}(001)$ в температурном диапазоне $T=1200 \ldots 1960 \mathrm{~K}$ при давлении $p \leq 10^{-4}$ Па. Показана взаимосвязь структуры и состава монокристаллических образцов боридов лютеция с их термоэмиссионными характеристиками. На основе теоретических расчетов ретикулярной плотности ионов металла и бора и электрического дипольного момента неперестроенных поверхностей (100), (110), (111) решетки типа $\mathrm{UB}_{12}$ объяснена анизотропия работы выхода электрона низкоиндексных плоскостей монокристаллов $\mathrm{LuB}_{12}$.

Термоемісійні властивості монокристалів боридів лютецію. Д.О.Воронович, А.О.Таран, Н.Ю.Шіцевалова, Г.В.Левченко, В.Б.Філіпов.

Представлено результати досліджень термоемісійних властивостей LuB 12 (100), (110), (111), LuB $_{4}(001)$, LuB $_{2}$ (001) у температурному діапазоні $T=1200 \ldots 1960 \mathrm{~K}$ при тиску $p \leq 10^{-4}$ Па. Показано взаємозв'язок структури і складу монокристалічних зразків боридів лютецію з їх термоемісійними характеристиками. На основі теоретичних розрахунків ретикулярної густини іонів металу і бору та електричного дипольного моменту неперебудованих поверхонь (100), (110), (111) гратки типу UB 12 пояснено анізотропію роботи виходу електрона низькоіндексних площин монокристалів LuB $_{12}$.

\section{Introduction}

Four binary compounds: lutetium di-, tetra-, dodeca- and hectoboride $\left(\mathrm{LuB}_{2}, \mathrm{LuB}_{4}\right.$, $\mathrm{LuB}_{12}$ and $\mathrm{LuB}_{66}$, accordingly) - are known among Lu-B systems [1]. Thermionic emission properties were studied only for $\mathrm{LuB}_{12}$, and the investigations have been performed with polycrystalline samples [2].

Earlier the thermionic properties anisotropy of low-index crystallographic planes of erbium dodecaboride $\mathrm{ErB}_{12}$ was experimentally investigated [3]. The boron and erbium reticular densities $\left(d_{r}\right)$ (number of atoms 
(ions) per unit area in any plane of a crystal lattice) in $\mathrm{ErB}_{12}$ low-index planes were considered in [3] and it was shown that decreasing of electron work function for the $\mathrm{ErB}_{12}$ crystallographic planes in row $(100) \rightarrow(110) \rightarrow(111)$ correlates with the following decreasing of reticular densities $d_{r}(\mathrm{~B}) / d_{r}(\mathrm{Er})$ ratio: $4 \rightarrow 2 \rightarrow 0$. Taking into account that $\mathrm{LuB}_{12}$, as well as $\mathrm{ErB}_{12}$, crystallizes in a face-centered cubic lattice of $\mathrm{UB}_{12}$ crystal structure type (space group $\left.F m 3 m-O_{h}^{5}\right)$ [4] it can be supposed that decreasing of the electron work function for the $\mathrm{LuB}_{12}$ low-index planes is similar to ones of the corresponding $\mathrm{ErB}_{12}$ planes. Reasons of the thermionic properties anisotropy for dodecaborides with $\mathrm{UB}_{12}$-type lattice are unclear.

Lanthanum hexaboride is the most studied thermionic material among borides. Its lower values of the electron work function for (100) and (110) planes in comparison with the (111) one are caused by electric dipole moment of dipoles formed from surface positively charged lanthanum ions and the nearest to them negatively charged $B_{6}$ octahedra [5,6]. The surface of $\operatorname{LaB}_{6}(100)$ consists of La atoms layer, under it the octahedra $B_{6}$ layer is situated at a distance of $2.08 \AA$ (half of the $\mathrm{LaB}_{6}$ lattice constant). The surface atoms of $\mathrm{La}$ in $\mathrm{LaB}_{6}(110)$ are displaced outwards at $1.66 \AA$ in relation to the $B_{6}$ octahedra layer. Therefore the electric dipole moment of the $\mathrm{LaB}_{6}(110)$ surface layer is less than of the (100) one. The surface atoms of $\mathrm{La}$ in $\mathrm{LaB}_{6}(111)$ are displaced outwards at $1.2 \AA$ relative to their positions in the ideal lattice and situated at grade with the $B_{6}$ octahedra layer. And so the electric dipole moment of $\mathrm{LaB}_{6}$ (111) surface layer equals zero. The greater is the electric dipole moment of the $\mathrm{LaB}_{6}$ surface layer, the less the electron work function $\varphi$ is.

It is very likely that the thermionic properties anisotropy of $\mathrm{LuB}_{12}$ single crystal unreconstructed surfaces also is governed by different values of the surface electric dipole moment.

The aims of this work are:

- experimental research of the electron work function temperature dependences of $\mathrm{LuB}_{12}$ (100), (110) and (111); LuB 4 (001), $\mathrm{LuB}_{2}(001)$ at $p \leq 10^{-4} \mathrm{~Pa}$ pressure in the temperature range $T=1200 \ldots 1960 \mathrm{~K}$;

- study of the thermionic properties anisotropy of the $\mathrm{LuB}_{12}$ low-index planes;
- calculation of the electric dipole moment of the unreconstructed (100), (110), (111) $\mathrm{LuB}_{12}$ surfaces;

- measurement of the evaporation rate of lutetium boride single crystals;

- investigation of interrelation between structure and composition of lutetium borides with their thermionic properties before and after thermionic tests.

\section{Experimental}

Lutetium borides $\mathrm{LuB}_{12}, \mathrm{LuB}_{4}$ and $\mathrm{LuB}_{2}$ investigated in this study were grown by crucible free inductive zone melting. The preparation peculiarities and structure examination of the produced single crystals are presented in [7]. The experimental equipment and thermionic properties research procedure of the lutetium borides single-crystal samples were the same as for ErB $_{12}$ single crystals [3].

The evaporation rate $G$ of the investigated lutetium borides single crystals was determined by rate of a weight loss obtained as a difference between the specimen weight before and after heating.

The evaporation rate of the most substances may be expressed by the following relation

$$
\lg G=C-0.5 \lg T-(B / T),
$$

where $G$ is in grams per square centimeter per second at temperature $T$ in kelvins, $C$ and $B$ are empirical constants [8]. For example, for $\mathrm{LaB}_{6} C=13$ and $B=36850 \mathrm{~K}$. With increasing temperature the evaporation rate significantly increases and the main weight loss takes place at high temperatures. At the same time a prolonged heating at lower temperatures may result in the same values of a weight loss. Therefore hereinafter $G$ is given either after the highest working temperatures for $\mathrm{LuB}_{12}(100)$, $\mathrm{LuB}_{4}(001)$, or after the prolonged heating at the lower temperatures for $\mathrm{LuB}_{12}$ (111) and (110), $\mathrm{LuB}_{2}(001)$. The relative error of $G$ determination is $30 \%$.

\section{Results and discussion}

It is known that temperature dependences of the electron work function of the most studied borides are described by linear functions in a certain temperature range [9]. Therefore it we can expect that $\varphi(T)$ dependences of the studied lutetium borides specimens will be described by linear functions in the certain temperature ranges too. 
It is also known that metal content in emitting surface plays the main role in thermionic activity of boride cathodes. The planes (001) of $\mathrm{LuB}_{4}$ and $\mathrm{LuB}_{2}$ lattices are composed only of lutetium atoms [10]. Although anisotropy of the $\mathrm{LuB}_{4}$ and $\mathrm{LuB}_{2}$ thermionic properties has not yet been studied it is supposed that the $\mathrm{LuB}_{4}$ and $\mathrm{LuB}_{2}$ highest thermionic currents will be just for (001) plane.

At first let's consider results of the study of $L \mathrm{BB}_{12}$ single-crystal thermionic. Measurements of the $L^{-B_{12}}$ (100), (110) and (111) thermionic current were performed with increasing temperature in the range of $T=1220 \ldots 1960 \mathrm{~K}$ during $7 \mathrm{~h}$. The $\varphi(T)$ dependences calculated by use of current values are presented in Fig. 1. The equations describing $\varphi(T)$ dependence for different low-index crystallographic planes of $L \mathrm{BB}_{12}$, values of the thermionic current densities $j$ and according $\varphi$ at $1800 \mathrm{~K}$, the rates of evaporation at $1900 \mathrm{~K}$ and calculated values of $j$ for polycrystalline $L \mathrm{BB}_{12}$ by use of data from [2] are presented in Table 1. As in the case of polycrystalline $\mathrm{LuB}_{12}$ the electron work function temperature dependences $\varphi(T)$ for $L \mathrm{BB}_{12}$ (100), (110), (111) are described by the linear functions in the certain temperature ranges.

As can be seen from the experimental results the electron work function decreases in the series $(100) \rightarrow(110) \rightarrow(111)$. It is in a good agreement with decreasing of $d_{r}(\mathrm{~B}) / d_{r}(\mathrm{Me})$ ratio for low-index planes of $\mathrm{UB}_{12}$ - type lattice in the same series [3]. The boride electron work function anisotropy is conditioned on $\varphi$ dependence on the surface $d_{r}(\mathrm{~B}) / d_{r}(\mathrm{Me})$ ratio and the electric dipole moment of the surface dipole per one metal ion [6]. The dipole contribution $\Delta \varphi_{D}$ to the electron work function is propor-

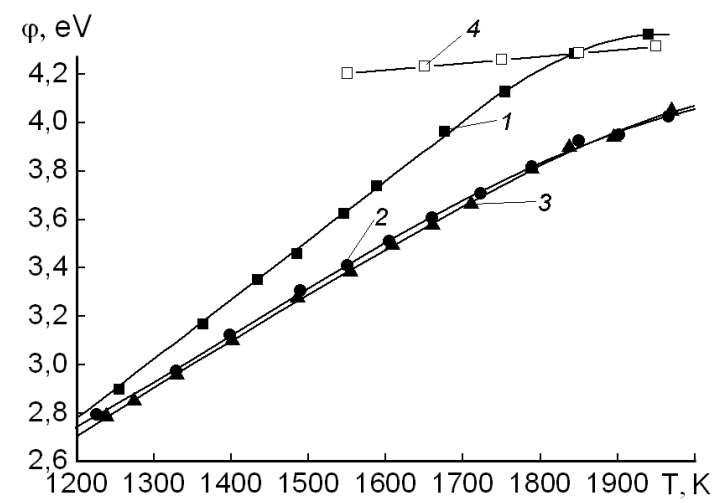

Fig. 1. Temperature dependences of $\mathrm{LuB}_{12}$ electron work function: $1-(100), 2-(110)$, 3 - (111), 4 - polycrystal [2].

tional to reticular density of the metal ions $d_{r}$ and normal component of the electric dipole moment of the surface dipole $p_{e}$ per metal ion [11]:

$$
\begin{gathered}
\Delta \varphi_{D}=-\frac{d_{r} p_{e}}{\varepsilon_{0}}, \\
p_{e}=\frac{q}{N} \sum_{i=1}^{N} r_{i} \cos \theta_{i},
\end{gathered}
$$

where $\varepsilon_{0}=8.85 \cdot 10^{-12} \mathrm{~F} \cdot \mathrm{m}^{-1}$ is the electric constant, $q$ is the effective charge of a metal ion (in coulombs), $N$ is the quantity of $B_{12}$ cubooctahedra nearest to the metal ion on the surface, $r_{i}$ is the distance between metal ion and nearest $i$ th $B_{12}$ cubooctahedron, $\theta_{i}$ is the angle between the direction from the metal ion to $i$ th $\mathrm{B}_{12}$ cubooctahedron and the surface normal n. Using $\mathrm{LuB}_{12}$ three-dimensional modeling and its lattice parameter [4] it was obtained that the quantity of the $B_{12}$ cubooctahedra nearest to the metal ion is equal to $5,4,3$ for

Table 1. Thermionic properties and evaporation rates of low-index crystallographic planes of

\begin{tabular}{|c|c|c|c|c|}
\hline \multirow[t]{2}{*}{ Characteristics } & \multicolumn{4}{|c|}{$\mathrm{LuB}_{12}$} \\
\hline & $(100)$ & (110) & (111) & polycrystal [2] \\
\hline$\varphi(T), \mathrm{eV}$ & $-0.16+24.5 \cdot 10^{-4} T$ & $0.49+18.8 \cdot 10^{-4} T$ & $0.50+18.5 \cdot 10^{-4} T$ & $3.77+2.8 \cdot 10^{-4} T$ \\
\hline$T, \mathrm{~K}$ & \multicolumn{2}{|c|}{$1220 \ldots 1800$} & \multicolumn{2}{|c|}{$1550 \ldots 1950$} \\
\hline$\varphi, \mathrm{eV}(T=1800 \mathrm{~K})$ & 4.25 & 3.87 & 3.83 & 4.27 \\
\hline $\begin{array}{c}j, \mathrm{~A} \cdot \mathrm{cm}^{-2} \\
(T=1800 \mathrm{~K})\end{array}$ & $4.9 \cdot 10^{-4}$ & $5.7 \cdot 10^{-3}$ & $7.4 \cdot 10^{-3}$ & $4.3 \cdot 10^{-4}$ \\
\hline $\begin{array}{c}G, 10^{-7} \mathrm{~kg} \cdot \mathrm{m}^{-2} \cdot \mathrm{s}^{-1} \\
(T=1900 \mathrm{~K} \\
\left.p \sim 10^{-4} \mathrm{~Pa}\right)\end{array}$ & 25.3 & 9.4 & 14.4 & - \\
\hline
\end{tabular}
lutetium dodecaboride 


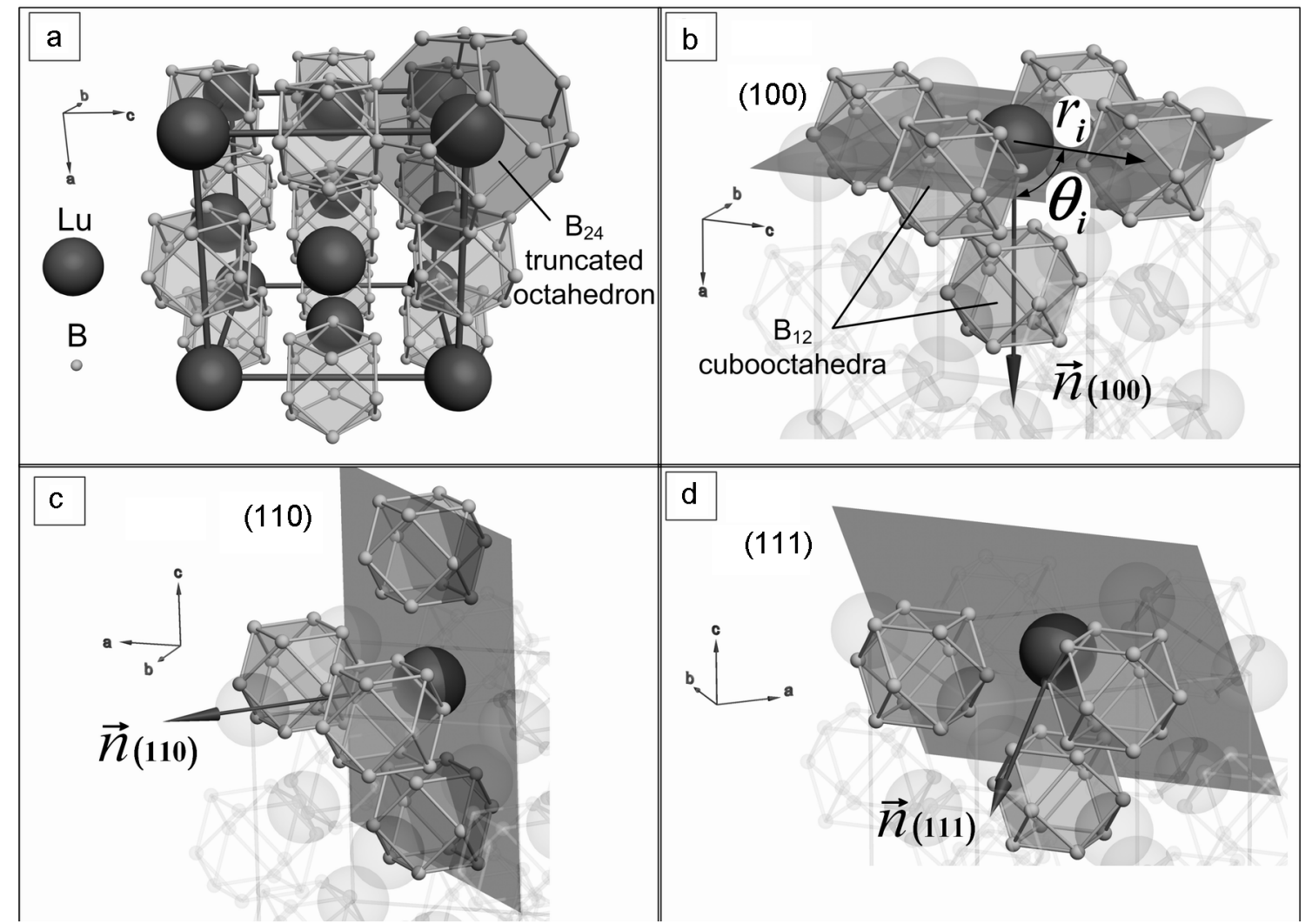

Fig. 2. Fragments of $3 \mathrm{D}$ model of $\mathrm{LuB}_{12}$ crystal structure and its basal (100), (110), (111) planes centered on metal ion with the nearest to it $B_{12}$ cubooctahedra both in plane and outside it: a unit cell, b - (100), c - (110), d - (111).

each metal ion located in (100), (110) and (111) planes accordingly (see Fig. 2). Taking into account the metal ions reticular density from [3] and the lattice constant $a$ (for $\left.\mathrm{LuB}_{12} a=074646 \AA[4]\right)$ the value of $\Delta \varphi_{D}$ is obtained (Table 2). As it should be from calculations for the low-index planes of $\mathrm{UB}_{12^{-}}$ type lattice a metal enrichment of crystallographic plane results in the surface electric dipole moment increase and the corresponding electron work function decrease. In particular $\Delta \varphi_{D}$ decrease for $L \mathrm{BB}_{12}$ in series $(100) \rightarrow(110) \rightarrow(111)$ correlates with the electron work function decrease that has been observed experimentally
(Fig. 1). At the same time in spite of essential difference between $\Delta \varphi_{D}$ for (110) and (111) (Table 2), $\varphi(T)$ values for these planes are almost the same (Fig. 1). This is may be due to the fact that there is displacement of the near-surface $\mathrm{Lu}$ ions outward the surface that results in a difference in values of the electric dipole moment of surface dipoles in the real and ideal crystal structures. It is necessary to note the direct experimental measurements of $p_{e}$ have not been performed to present day.

A deviation from the $\varphi(T)$ linear dependence takes place with increasing temperature above $T>1800 \mathrm{~K}$ for all low-index planes of $\mathrm{LuB}_{12}$ (Fig. 1). Earlier it was es-

Table 2. Some characteristics of low-index crystallographic planes of $U_{12}$-type lattice

\begin{tabular}{||c|c|c|c|c|c||}
\hline \multirow{2}{*}{$\begin{array}{c}\text { Crystallographic } \\
\text { plane }\end{array}$} & \multicolumn{2}{|c|}{ Reticular density $d_{r}, a^{-2}$} & $d_{r}(\mathrm{~B}) / d_{r}(\mathrm{Me})$ & $p_{e}, q \cdot a$ & $\Delta \varphi_{D}, q / \varepsilon_{0} a$ \\
\cline { 2 - 3 } & $\mathrm{B}$ & $\mathrm{Me}$ & & & -0.2 \\
\hline$(100)$ & 8 & 2 & 4 & 0.1 & -0.25 \\
$(110)$ & $2 \sqrt{2}$ & $\sqrt{2}$ & 2 & $\sqrt{2} / 8$ & -0.33 \\
$(111)$ & 0 & $2 \sqrt{3} / 3$ & 0 & $\sqrt{3} / 6$ & \\
\hline
\end{tabular}




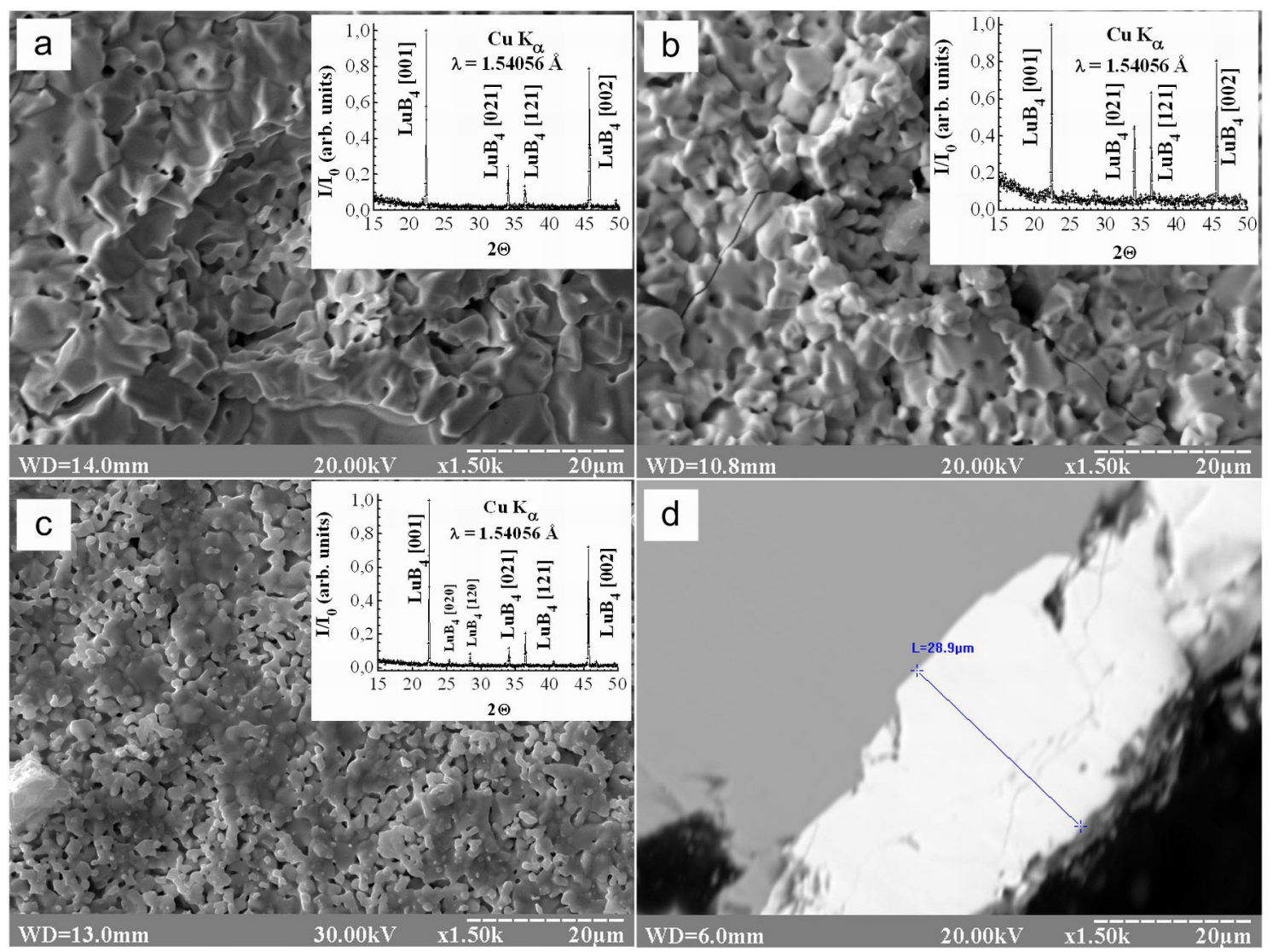

Fig. 3. SEM images of the samples surfaces covered by $L \mathrm{~B}_{4}$ layer after thermionic investigations and corresponding X-ray diffraction patterns (inserts): a $-[100], b-[110], c-[111], d-$ longitudinal section of $\mathrm{LuB}_{12}$ [111] cathode with near-surface layer $\mathrm{LuB}_{4}$ (details are in the text).

tablished [10] that on $\mathrm{LuB}_{12}$ heating in the range of $T=1400 \ldots 1800 \mathrm{~K}$ the surface restructuring takes place with $\mathrm{LuB}_{4}$ phase formation in the surface layer due to preferential boron evaporation. In doing so dislocations of the crystal lattice can be centers of the $\mathrm{LuB}_{4}$ phase nucleation. Taking into account the dislocations low density in the studied $L_{12}$ single crystals (less than $10^{6} \mathrm{~cm}^{-2}$, i. e. an average distance between adjacent dislocations equals $\sim 10 \mu \mathrm{m}$ [7]), we can assume that at the initial heating of $L^{2 u B_{12}}$ single crystals in the range of $T=1400 . .1800 \mathrm{~K}$ the emitting surface have consisted of the starting $L^{2 u B_{12}}$ phase and $L \mathrm{BB}_{4}$ phase appeared during heating. As shown in [3] the nonlinearity $\varphi(T)$ of this surface consisting of tetra- and dodecaboride can be caused due to extension of the surface area with tetraboride with increasing temperature (or during prolonged annealing).

After thermionic current measurements in the range of $T=1220 . .1960 \mathrm{~K}$ during $7 \mathrm{~h}$ the additional annealing of the $\mathrm{LuB}_{12}$ single-crystal samples with different orien- tation was performed to establish how modification of the structure and phase composition of the surface affects on the thermionic properties. Annealing duration and temperature values were $t=10 \mathrm{~h}, T=1550 \mathrm{~K}$ for $L^{2 u B}{ }_{12}(100) ; t=40 \mathrm{~h}, T=1900 \mathrm{~K}$ for $\mathrm{LuB}_{12}$ (110) and (111). It was cleared up that the annealing results in formation of the lutetium tetraboride layer with corallike structure and $\approx 30 \mu \mathrm{m}$ thick at the starting $L \mathrm{BB}_{12}$ surface (Fig. 3).

The $\varphi(T)$ temperature dependences of such $L u B_{12}$ samples with the formed $\mathrm{LuB}_{4}$ surface layer are presented in Fig. 4, a. These dependences were obtained both at the temperature increase and decrease. Due to phase transformation $\mathrm{LuB}_{12} \rightarrow \mathrm{LuB}_{4}$ and structure restructurings of the near-surface layer the electron work function decreased compared with the starting $L \mathrm{~B}_{12}$. For instance the electron work function for the starting $\mathrm{LuB}_{12}$ (100) decreased by $0.88 \mathrm{eV}$ at $T=1900 \mathrm{~K}$. Irrespective of the initial orientation of the $L u B_{12}$ single-crystal samples after annealing their $\varphi(T)$ are described by the linear functions. 
After annealing all samples of the starting $\mathrm{LuB}_{12}$ were characterized by different values of the electron work function that is apparently determined by two factors: by various $\mathrm{LuB}_{4}$ crystallographic facets on the emitting surface (inserts on Fig. 3) to a greater extent; by effective area enlargement of the emitting surface owing to its coral-like structure to a lesser extent.

It is known [6] that activation energy of lanthanum atoms evaporation for the $\mathrm{LaB}_{6}$ low-index crystal faces is almost the same. At the same time the activation energy of boron atoms evaporation depends on the surface orientation. We suppose that the similar dependence takes place for $\mathrm{LuB}_{4}$ crystal too i.e. the activation energy of the boron atoms evaporation depends on the emitting surface orientation that results in thermal faceting of the emitting surface and as a consequence the different electron work function of the $\mathrm{LuB}_{12}$ samples covered by $\mathrm{LuB}_{4}$ layer after annealing.

Next stage of the researches was related with the current density measurements and electron work function calculation for (001) plane of the specially grown $\mathrm{LuB}_{4}[001]$ single-crystal. At first the thermionic properties of $\mathrm{LuB}_{4}(001)$ were investigated with increasing temperature in the range of $T=1240 \ldots 1910 \mathrm{~K}$ during $3 \mathrm{~h}$. The $\varphi(T)$ dependence of the starting $\mathrm{LuB}_{4}$ (001) (Fig. 4, b) is described by nonlinear function and themselves the starting $\varphi$ values differ from the $\varphi$ values of $\mathrm{LuB}_{4}$ formed on the annealed LuB $_{12}$ surface (Fig. 4, a).

The obtained difference in the $\varphi$ values is explained by the structure and phase composition modification of the $\mathrm{LuB}_{4}$ [001] crystal under heating in vacuum. Due to the preferential boron evaporation $\mathrm{LuB}_{4} \rightarrow \mathrm{LuB}_{2}$ phase transformation took place [10]. Subsequent $\mathrm{LuB}_{4}[001]$ annealing at $T=1500 \mathrm{~K}$ during $8 \mathrm{~h}$ resulted in increase of the thermionic current. After annealing the $\mathrm{LuB}_{4}$ $\varphi(T)$ dependence had loop - shape form with increasing temperature to $1900 \mathrm{~K}$ and subsequent its decrease (Fig. 4, b). This $\varphi(T)$ peculiarity may be explained by assumption that lutetium flow rises from the bulk towards the emitting surface with increasing temperature, at the same time boron evaporation prevails from the surface that results in lutetium enrichment of the surface and the thermionic current increases accordingly. With temperature decreasing the thermionic current values are higher than at the previous temperature in-
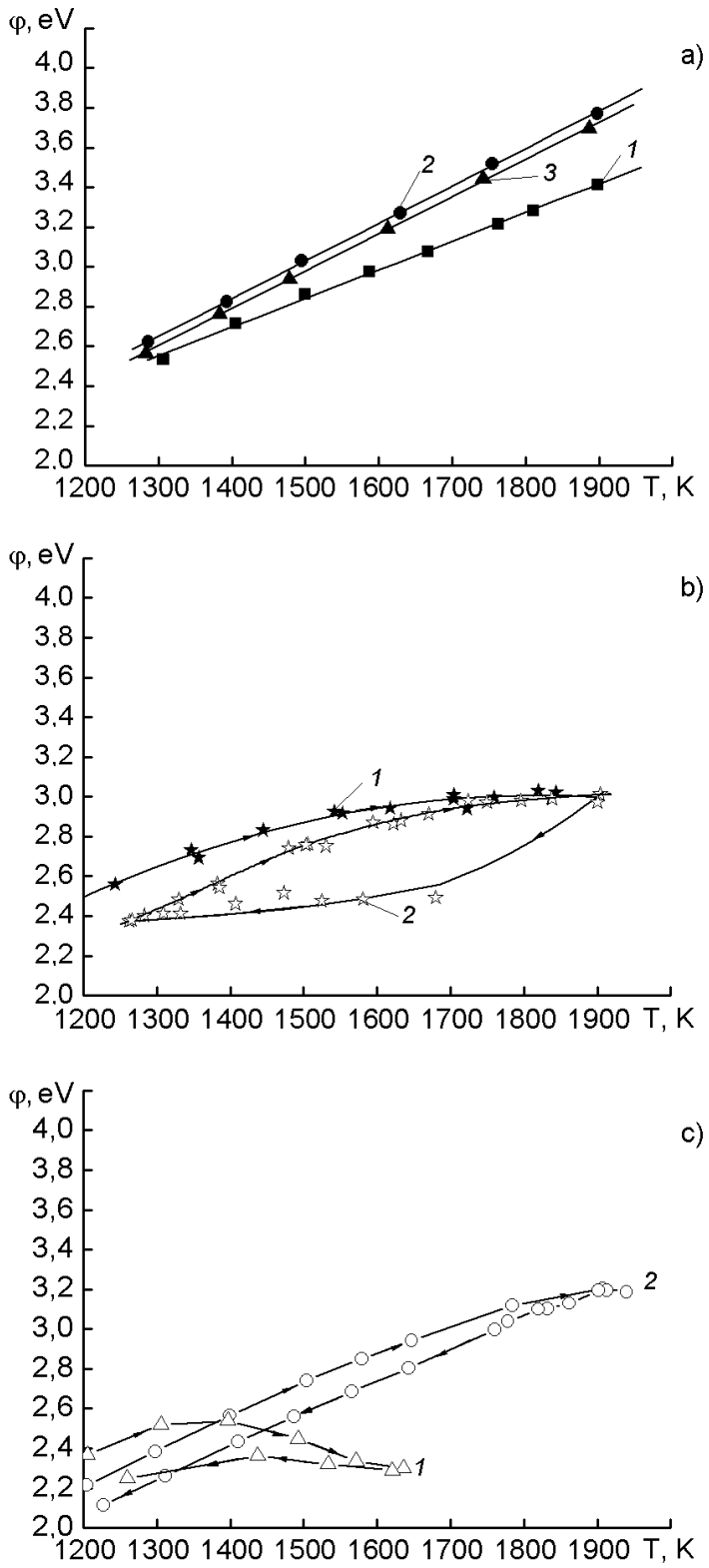

Fig. 4. Temperature dependences of the electron work function: a $-\mathrm{LuB}_{12}$ samples after annealing covered by $\mathrm{LuB}_{4}$ layer: $1-[100]$, 2 - [110], $3-$ [111];

b - LuB $_{4}$ [001] sample: 1-source, 2 after annealing covered by $\mathrm{LuB}_{2}$ layer; c - $\mathrm{LuB}_{2}$ [001] sample: $1-$ source, $2-$ after annealing.

crease due to the "frozen" heightened content of lutetium at the surface. According to X-ray phase and microprobe analyses the $\mathrm{LuB}_{4}$ surface layer after annealing consisted of polycrystalline $\mathrm{LuB}_{2}$ only (Fig. 5, a).

It should be noted that $\mathrm{LuB}_{4} \rightarrow \mathrm{LuB}_{2}$ phase transformation took place not only at the surface but also in the volume with formation of the like-directed $\mathrm{LuB}_{2}$ lamellae 

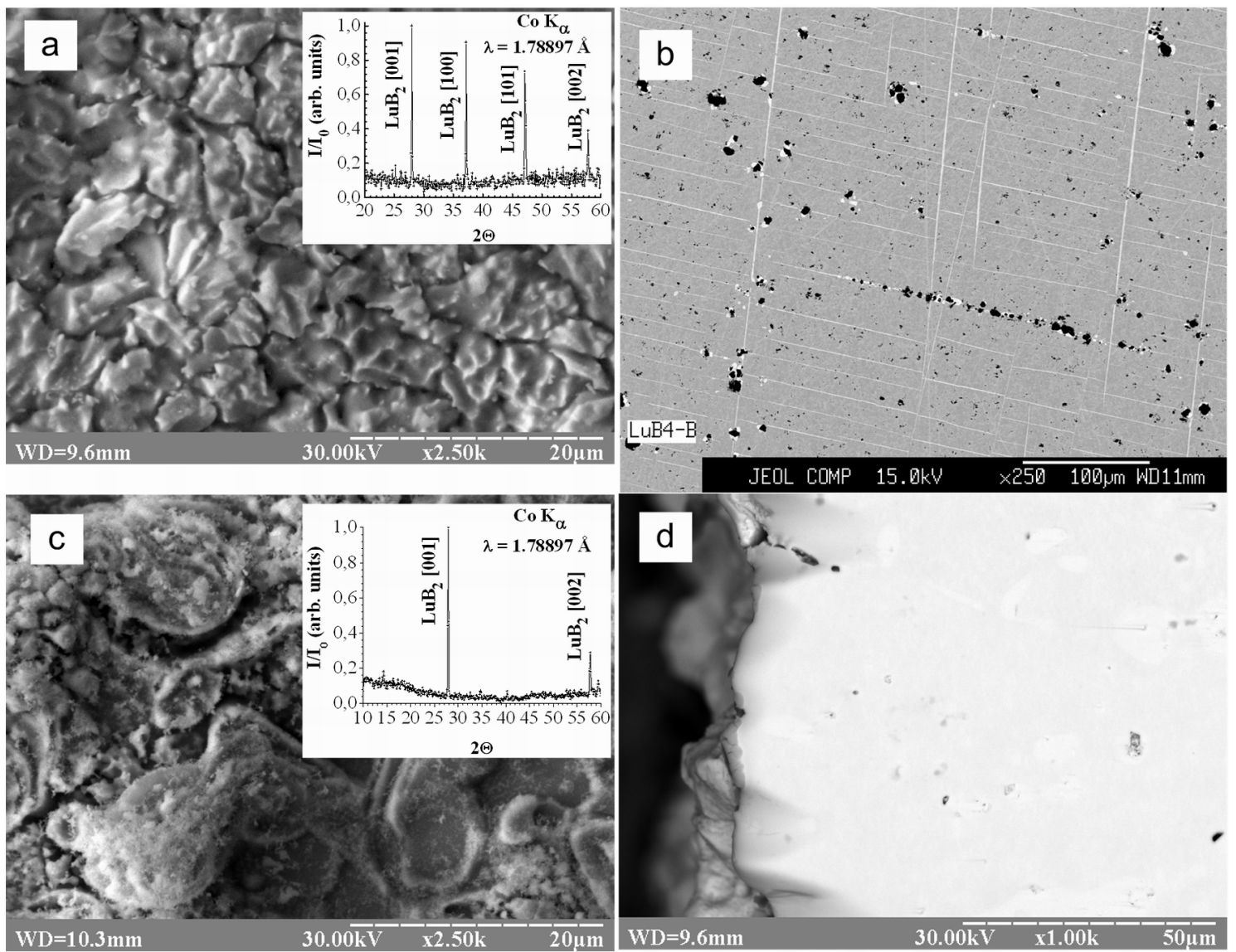

Fig. 5. SEM images and X-ray diffraction patterns (insert): a $-\mathrm{LuB}_{2}$ at surface of $\mathrm{LuB}_{4}[001], \mathrm{b}-$ longitudinal section of $\mathrm{LuB}_{4}[001]$ with $\mathrm{LuB}_{2}$ lamellae, c $-\mathrm{LuB}_{2}(001)$ after annealing, $\mathrm{d}-$ cross-section of $\mathrm{LuB}_{2}$ [001] near-surface layer.

(Fig. 5, b). Therefore the thermionic current of the starting $\mathrm{LuB}_{4}$ sample after annealing is defined both the $\mathrm{LuB}_{2}$ thermionic properties and boron diffusion towards the emitting surface through the $\mathrm{LuB}_{2}-\mathrm{LuB}_{4}$ interface boundary and along interface boundaries of the $\mathrm{LuB}_{2}$ lamellae from $\mathrm{LuB}_{4}$ volume. The $\mathrm{LuB}_{4}(001)$ evaporation rate equal $G=8.9 \cdot 10^{-7} \mathrm{~kg} \cdot \mathrm{m}^{-2} \cdot \mathrm{s}^{-1}$ at $T=1900 \mathrm{~K}$ was less than one for the $\mathrm{LuB}_{12}$ low-index planes of (see Table 1) that resulted in formation of the stable $\mathrm{LuB}_{4}$ layer on the $\mathrm{LuB}_{12}$ crystal surface on heating in vacuum.

To clarify the origin of the $\mathrm{LuB}_{4}$ thermionic properties with the emitting surface recovered by the $\mathrm{LuB}_{2}$ phase that had been generated due to heating of $\mathrm{LuB}_{4}$ during tests, the $\mathrm{LuB}_{2}$ [001] single-crystal was grown and its thermionic properties were investigated in the temperature range of $T=1200 \ldots 1940 \mathrm{~K}$. At first temperature was increased to $1635 \mathrm{~K}$ during $5 \mathrm{~h}$ and then it was decreased to $1259 \mathrm{~K}$ during $1 \mathrm{~h}$. The results of measurements showed the nonlinear $\varphi(T)$ dependence for $\mathrm{LuB}_{2}(001)$
(Fig. 4, c) and the larger thermionic current values compared with the current values of the $\mathrm{LuB}_{2}$ layer generated on the $\mathrm{LuB}_{4}$ sample. The highest thermionic current density was equal to $27 \mathrm{~A} \cdot \mathrm{cm}^{-2}(\varphi=2.30 \mathrm{eV})$ at $1635 \mathrm{~K}$. Taking into account that some metal diborides with $\mathrm{AlB}_{2}$-type lattice are characterized by cationic non-stoichiometry [12] one can suppose that the preferential lutetium diffusion towards the surface from the near-surface layer takes place under $\mathrm{LuB}_{2}$ heating that results in the thermionic current increase and electron work function decrease.

At the following stage the $\mathrm{LuB}_{2}[001]$ annealing was carried out under $T=1900 \mathrm{~K}$ during $4 \mathrm{~h}$. After annealing the obtained electron work function values were greater than before annealing (Fig. 4, c). According to the results of scanning electron microscopy with energy dispersive $\mathrm{X}$-ray analysis the $\mathrm{LuB}_{2}$ surface restructuring took place (Fig. 5, c). In doing so the individual boron layer approximately $0.3 \mu \mathrm{m}$ in thick was formed at the crystal surface due to prefer- 
ential lutetium evaporation and under this layer it was situated the layer enriched by boron approximately $5 \mu \mathrm{m}$ in thick (Fig. 5 , d). At the same time the $\mathrm{X}$-ray phase analysis detected only $\mathrm{LuB}_{2}$ (001) (insert in Fig. 5, c) because the boron layer of such size is transparent to X-rays.

The $\varphi(T)$ dependences for $\mathrm{LuB}_{2}(001)$ both before annealing and after were obtained at temperature increase and decrease and they differ from each other (Fig. 4, c). The lower values of the electron work function correspond to the temperature decrease. Probable explanation of this phenomenon is that the temperature increase makes for increase of the lutetium diffusion velocity towards the surface resulting in the high metal concentration in the near-surface layer. With decreasing temperature the evaporation rate diminishes and the greater lutetium concentration defines the lower $\varphi(T)$ values.

For $\mathrm{LuB}_{2}(001)$ the evaporation rate value is equal to $G=8.6 \cdot 10^{-7} \mathrm{~kg} \cdot \mathrm{m}^{-2} \cdot \mathrm{s}^{-1}$ at $T=1900 \mathrm{~K}$ that practically amounts the $G$ value for $\mathrm{LuB}_{4}(001)$. This fact explains formation of the stable $\mathrm{LuB}_{2}$ surface layer at the $\mathrm{LuB}_{4}$ sample.

\section{Conclusions}

For the first time the thermionic properties of $\mathrm{LuB}_{12}$ (100), (110) and (111); $\mathrm{LuB}_{4}(001)$ and $\mathrm{LuB}_{2}(001)$ are studied. The electron work function of the $\mathrm{LuB}_{12}$ low-index planes increases in series $(100) \rightarrow(110) \rightarrow(111)$. This reduction correlates with a decrease of the reticular densities $d_{r}(\mathrm{~B}) / d_{r}(\mathrm{Er})$ ratio and an increase of the surface electric dipole moment in the same series. Preferential boron evaporation from the surfaces of $\mathrm{LuB}_{12}$ and $\mathrm{LuB}_{4}$ borides results in the surface lutetium enrichment and hence the thermionic current increase. This is supported by reduction of the electron work function under $\mathrm{LuB}_{12} \rightarrow \mathrm{LuB}_{4}$ and $\mathrm{LuB}_{4} \rightarrow \mathrm{LuB}_{2}$ phase transformations on the surfaces of $\mathrm{LuB}_{12}$ and $\mathrm{LuB}_{4}$ single crystals accordingly. $\mathrm{LuB}_{2}(001)$ is characterized by the highest thermionic current density (27 A.cm ${ }^{-2}$ at $T=1635 \mathrm{~K}$ ) among lutetium borides studied in this research and may be considered as perspective effective cathode material.

\section{References}

1. T.B.Massalski (Editor-in-Chief), Binary Alloy Phase Diagrams, 2-d ed. Plus Updates, ASM International, ASM CD-ROM, Ohio, USA (1996).

2. G.V.Samsonov, L.N.Okhremchuk, I.A.Podchernjaeva et al., Izv.AN SSSR Neorg. Mater., 10, 270 (1974).

3. D.Voronovich, A.Taran, N.Shitsevalova et al., Solid State Sci., 14, 1624 (2012).

4. H.Werheit, V.Filipov, K.Shirai et al., J.Phys.: Condens. Matter., 23, 065403 (2011).

5. R.Nishitani, M.Aono, T.Tanaka et al., Surface Sci., 93, 535 (1980).

6. L.W.Swanson, M.A.Gesley, P.R.Davis, Surface Sci., 107, 263 (1981).

7. D.A.Voronovich, A.A.Taran, N.Yu.Shitsevalova et al., Aerospace Technic and Technology, 4, 80 (2011).

8. J.M.Lafferty, J.Appl.Phys., 22, 299 (1951).

9. V.S.Fomenko, Emission Properties of Materials, Naukova Dumka, Kiev (1981) [in Russian].

10. A.Taran, D.Voronovich, N.Shitsevalova et al., Solid State Phen., 172-174, 464 (2011).

11. L.N.Dobretsov, M.V.Gomoyunova, Emission Elektronics, Nauka, Moscow (1966) [in Russian].

12. A.L.Ivanovskii, I.R.Shein, N.I.Medvedeva, Russ. Chem. Rev., 77, 467 (2008). 